Comparison of finite control set and hysteresis based model predictive control for NPC and T-Type converter in case of low carrier ratio

Stefan Walz, Giampaolo Buticchi, Marco Liserre

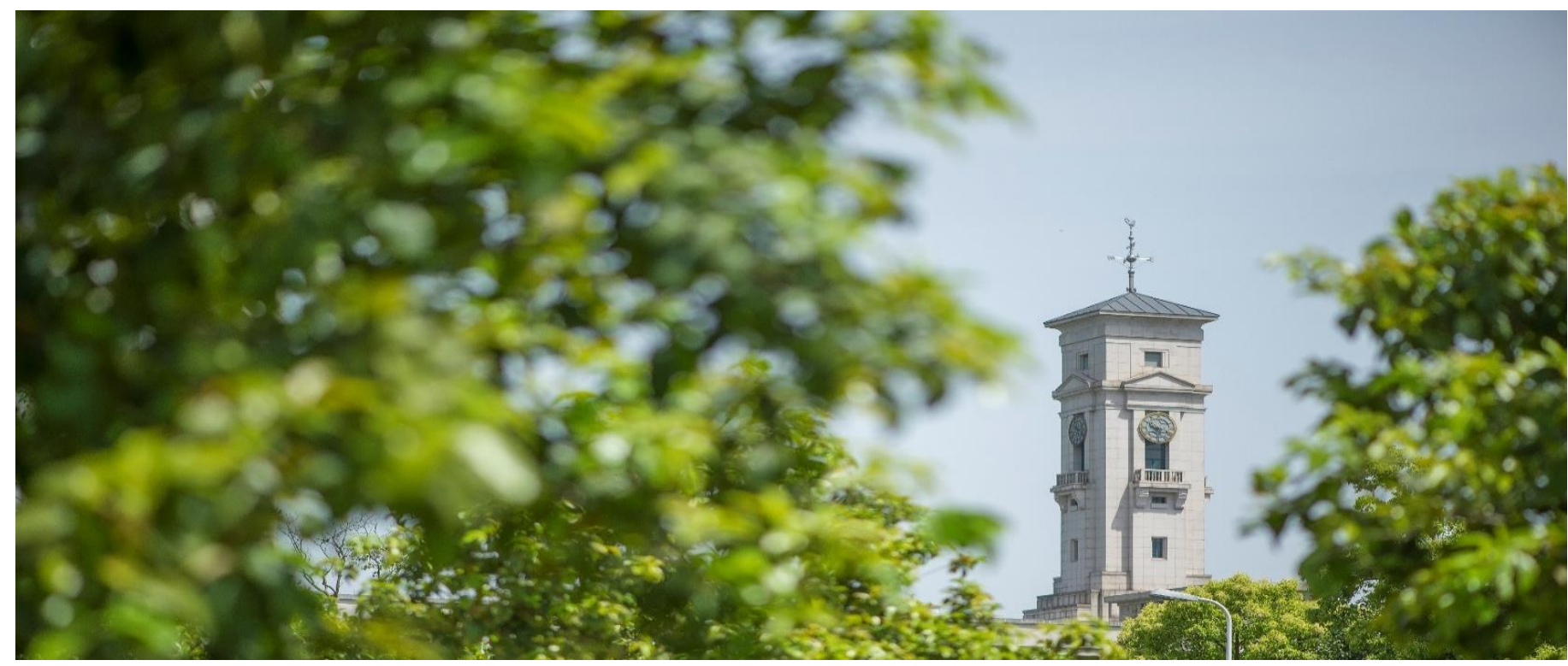


University of Nottingham Ningbo China, 199 Taikang East Road, Ningbo, 315100, Zhejiang, China.

First published 2019

This work is made available under the terms of the Creative Commons Attribution 4.0 International License:

http://creativecommons.org/licenses/by/4.0

The work is licenced to the University of Nottingham Ningbo China under the Global University Publication Licence:

https://www.nottingham.edu.cn/en/library/documents/researchsupport/global-university-publications-licence.pdf 


\section{Comparison of Finite Control Set and Hysteresis Based Model Predictive Control for NPC and T-Type Converter in case of low carrier ratio}

\author{
Stefan Walz \\ Chair of Power Electronics \\ Christian-Albrechts-Universität zu Kiel \\ Kiel, Germany \\ swa@tf.uni-kiel.de
}

\author{
Giampaolo Buticchi \\ PEMC Group \\ University of Nottingham Ningbo China \\ Ningbo, China \\ buticchi@ieee.org
}

\author{
Marco Liserre \\ Chair of Power Electronics \\ Christian-Albrechts-Universität zu Kiel \\ Kiel, Germany \\ ml@tf.uni-kiel.de
}

\begin{abstract}
The control of machines in case of low carrier ratio (ratio of switching frequency to electrical frequency $f_{s w} / f_{e l}$ ) is a challenging topic at the highly dynamic control of highspeed machines and high power converters. While common PI Controllers face stability issues at low ratios, Model Predictive Control (MPC) can be used to ensure stability. The cost function can be used, to reduce the Total Harmonic Distortion of the motor currents $\left(\mathbf{T H D}_{i}\right)$ or, keeping the $\mathbf{T H D}_{i}$ constant, reducing the motor filter size. This paper presents a comparison of Finite Control Set (FCS) and hysteresis based MPC algorithm for three level converter. The predictive control of the currents is providing good dynamic performance. The Neutral Point Clamped (NPC) or T-Type converter are considered to optimize the harmonic distortion of the permanent magnet synchronous motor (PMSM) currents. Simulation and experimental results prove the effectiveness of the analyzed control for 3-Level Converters.
\end{abstract}

Index Terms-Model Predictive Control, Hysteresis Based Control, Multilevel Converter, PMSM.

\section{INTRODUCTION}

Low carrier ratio, meaning low ratio of switching frequency to electrical frequency $\left(f_{e l} / f_{S}\right)$ is a challenging topic for applications like high-speed drives, or high power drives [1].

In the industry, for electrical drive applications a cascaded field-oriented control (FOC) is commonly used. Model predictive control offers the possibility to reduce the effective switching frequency of the converter while maintaining fast dynamic response, and good steady-state performance, which is important assuming a cascaded control structure [2]. The cost function can be used to optimize performance, losses, or increase robustness, but raises high computational requirements, for example shown for FCS MPC in [3]. On the other hand, deadbeat predictive control can be used to null the control error after a predefined number of switching periods and obtains very good dynamic performance. In [4] modulation and predictive current control for low switching frequencies are shown. In [5] a comparison of MPC schemes is given for medium voltage induction machines.

For multilevel converter the computational effort rises exponentially [6].
The paper structure is organized as follows: the system description, including the analyzed three level converters and motor equations is given in Section II. In Section III, the control structure of the hysteresis based Model predictive control is introduced and simulation results are given in Section IV. Experimental results are provided in Section $\mathrm{V}$ to validate the theoretical analysis. Conclusions are drawn in Section VII.

\section{SySTEM DESCRIPTION}

This section describes analyzed drive system with the two different 3-Level topologies, the NPC and T-Type. In Fig. 1 overview of the system configuration is given. The 3-Level Voltage Source Converter (VSC) is represented by the voltage vector hexagon. Different to PI based structures with PWM, the MPC is directly calculating the six duty cycles (plus six inverted) to control the IGBTs of the VCS. The processing and calculation period takes one sampling period. In (1) and (2) the motor equations for a digital control are given. The voltages are calculated based on the predicted currents and the output voltages based on the sampled values and are applied at the $(\mathrm{k}+2)$-th period. The measured values in the $\mathrm{k}$-th period are used for the calculations of the $(\mathrm{k}+1)$-th period and $i_{d q}^{*}(k)$ is used as reference currents.

$$
\begin{aligned}
v_{d}(k+1) & =\frac{L_{d}}{T_{S}}\left(i_{d}^{*}(k)-i_{d}(k+1)\right)+R_{s} i_{d}(k+1)- \\
& -L_{q} \omega_{e l} i_{q}(k+1) \\
v_{q}(k+1) & =\frac{L_{q}}{T_{S}}\left(i_{q}^{*}(k)-i_{q}(k+1)\right)+R_{s} i_{q}(k+1)+ \\
& +L_{d} \omega_{e l} i_{d}(k+1)+\omega_{e l} \Psi_{P M}
\end{aligned}
$$

The investigated NPC and T-Type converter are the most commonly used. Their schematic is given in Fig. 2 and Fig. 3. For the control of electrical machines, the PI Control is used since many decades in industry. With the use of digital systems, the Controller has to be discretized, for example using the Euler Methods. Using these methods, with lowering the pulse ratio, stability problems will occur. A way to overcome this problem, is the direct design of the PI Controller in 
the discrete time domain, as for example shown in [7]. This method is used for the comparisons in this paper.

\section{3-LeVEl Hysteresis BASED Model Predictive CONTROL}

The hysteresis based MPC (or MPC with bounds) uses the motor equation to predict the motor currents in the next control steps. If the absolute value of the predicted current is higher than the defined bounds, a new voltage vector will be applied, to keep the current trajectory inside the bounds. The current bounds are directly influencing the motor current harmonics, $\mathrm{THD}_{i}$. The cost function is designed to choose the voltage vector with the best ratio of periods that the trajectory will stay inside the bounds, compared to the switching instances needed to apply this voltage vector.

For three-level Converters, a good knowledge of the system parameters is required, to choose correctly of the 27 different voltage vectors. Parameters mismatches due to converter nonlinearities, deadtimes, or saturation have to be taken into account. Considering the low ratio of switching to electrical frequency $f_{s w, e f f} / f_{e l}$, it is also very important, that the angular displacement is compensated.

Based on the known last applied voltage vector $V^{\text {ind }}$ old, the current at the end of the sampling period, $i_{d q, p r e d}=$ $i_{d q}(k+1)$, can be predicted accurately based on the motor equations. Using the possible voltage vectors of the three-level converter, the current trajectories $T_{x}^{i}$ for the next sampling period are calculated. As there are redundant voltage vectors, these calculations have to be done 19 times, showing the increased computational effort for the three-level converters compared to the two-level with seven different voltage vectors. The current trajectories are predicted for example with an algorithm introduced by Bolognani, adapted here for the threelevel converter [8].

$$
\begin{aligned}
i_{d}^{i}(k+2) & =i_{d}(k+1)+\frac{T_{S}}{L_{d}}\left(V_{d}^{i}(k+1)-R_{s} i_{d}(k+1)\right. \\
& +\omega_{e l} L_{q} i_{q}(k+1) \\
i_{q}^{i}(k+2) & =i_{q}(k+1)+\frac{T_{S}}{L_{q}}\left(V_{q}^{i}(k+1)-R_{s} i_{q}(k+1)\right. \\
& -\omega_{e l} L_{d} i_{d}(k+1)-\omega_{e l} \Psi_{P M}
\end{aligned}
$$

By calculating the error amplitude and change of the error angle of each voltage vector, the trajectories are approximated as linear current curve.

$$
\begin{aligned}
T_{x}^{i} & =2 \cdot i_{\text {Bound }} \cdot \\
& \cdot \frac{\cos \left(\pi+\arctan \frac{i_{q}(k+1)-i_{q}^{i}(k+2)}{i_{d}(k+1)-i_{d}^{i}(k+2)}-\arctan \frac{i_{q}^{*}(k)-i_{q}(k+1)}{i_{d}^{*}(k)-i_{d}(k+1)}\right)}{\operatorname{abs}\left(i_{d q}(k+1)-i_{d q}^{i}(k+2)\right)}
\end{aligned}
$$

These calculations are executed in every sampling period. To make sure the current stays inside the bound at all time, the absolute value of the $d / q$-current error with the currently applied voltage vector is compared to the bound limit. In case this current $i^{i n d_{\text {old }}}(k+2)$ is bigger than the bound, a new voltage vector has to be applied. The cost function chooses the new index by maximizing the cost function, (6). For this the trajectories $T_{x}^{i}$ are normalized by the sampling time $T_{S}$. Additionally for redundant voltage vectors, the one with the least commutations should be applied. This means, choosing the voltage vector that will keep the trajectory inside the bounds the longest, but taking into account the number of switching instances $n_{\text {com }}$ to reach this state.

$$
i n d=\max _{i=[1 \ldots 27]}\left(\frac{\text { floor }\left(T_{x}^{i} / T_{S}\right)}{n_{\mathrm{com}}}\right)
$$

Even though the results can be fraction numbers, this term gives an idea of how many sampling periods per commutation the current will stay inside the bounds. For example, it is preferable to choose a voltage vector that keeps the current inside the bounds for three sampling periods with only one switching operation, instead of a voltage vector that provides five sampling periods but needs two commutations. Problems can occur, if two vectors provide the same number of periods. To prevent that in this case always the first solution is chosen, the cost function is extended by an correction term $c_{i}$. If two or more solutions are providing the same number of periods, the solution with the lease mean error should be chosen. For that the accumulated error $e_{i \text {,accum }}$ is divided by the predicted number of periods $n_{p}^{i}$ and added to the cost function (6). This ensures the best initial position for the next optimization step.

$$
c_{i}=\frac{\sum\left\|i_{d q}^{*}-i_{d q}^{i}\left(k+T_{n}\right)\right\|}{i_{\text {Bound }} \cdot n_{p}^{i}}
$$

\section{Finite Control Set Model Predictive Control}

Similar to the hys. based MPC, the FCS MPC algorithm is using the motor equations. The cost function of the FCS MPC is minimizing the tracking error of the motor currents. The effective switching frequency can be set by and additional term, which is penalizing switching operations by using the parameter $\lambda$, eq. (8).

$$
\begin{aligned}
& \min _{i=[1 \ldots 27]}\left\{J_{\mathrm{i}}\right\}= \\
& =\left(i_{d}^{*}(k)-i_{d}(k+1)\right)^{2}+\left(i_{q}^{*}(k)-i_{q}(k+1)\right)^{2}+\lambda \cdot \Delta V(k)
\end{aligned}
$$

For the cost function of the FCS MPC two terms, the tracking error and the penalty on switching are used. One advantage of the FCS MPC is that also other objectives can be included in the cost function, like temperature, power, or many other.

\section{Simulation Results}

The finite control set and hysteresis based MPC algorithms for NPC and T-Type are compared with a discrete-time current regulator, e.g. shown in [7]. The machine and converter parameter are givenin I and II. 


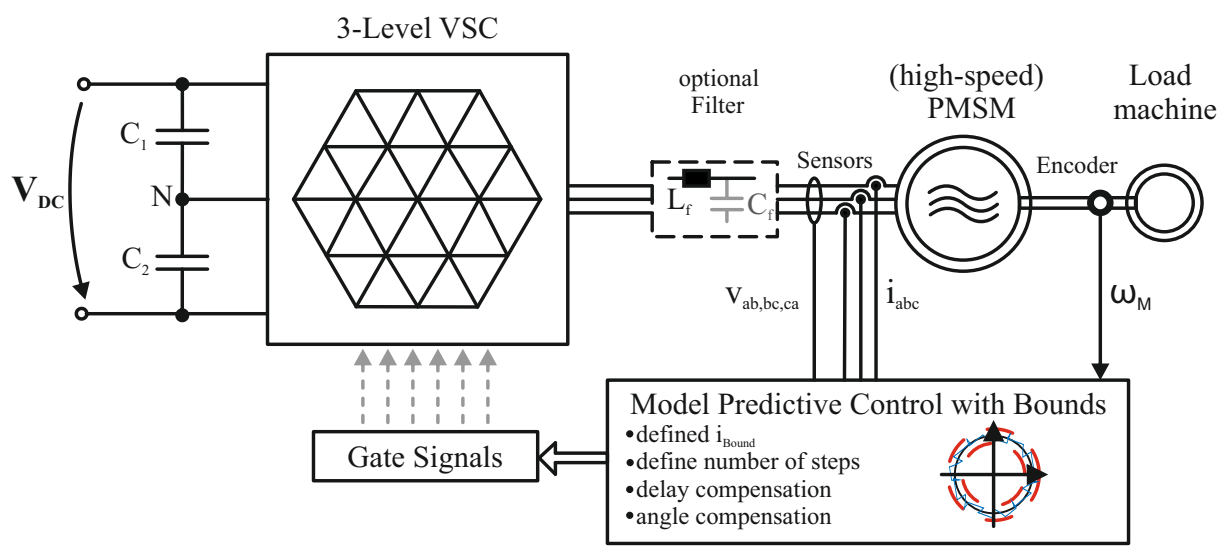

Fig. 1. Schematic of 3-Level Converter with MPC Control.

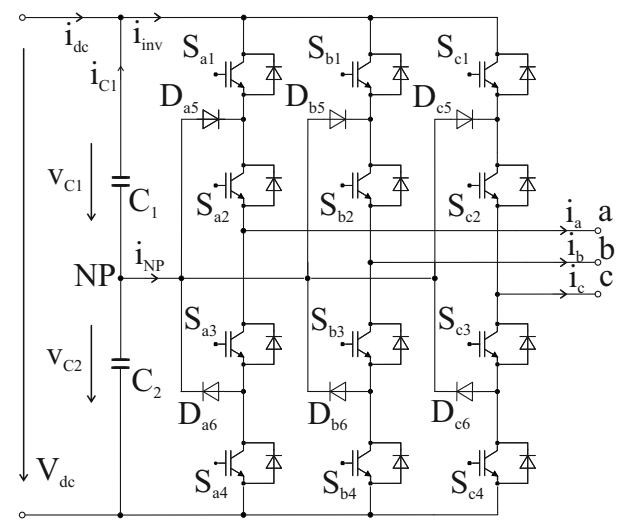

Fig. 2. 3-Level NPC with IGBTs.

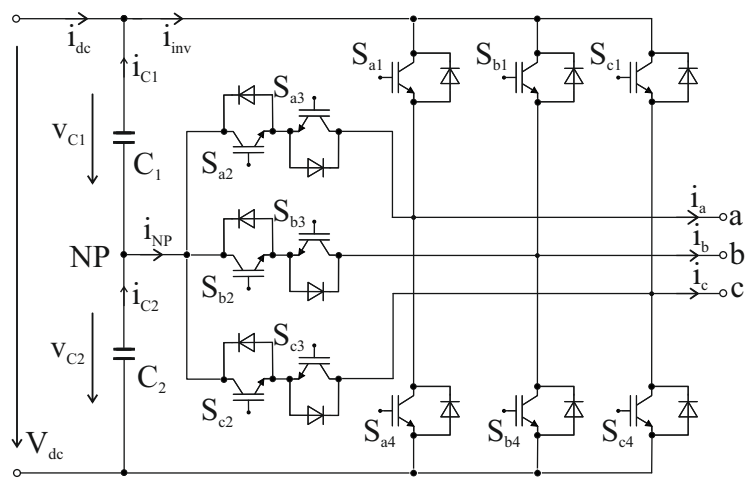

Fig. 3. 3-Level T-Type with IGBTs.

Figure 9 shows the THDi over the (effective) switching frequency, comparing the hysteresis based MPC with a sampling frequency of $f_{S}=20 \mathrm{kHz}$, and the direct designed PI Control at nominal speed, $\left(f_{e l}=100 \mathrm{~Hz}\right)$. The dashed lines shown the simulation results. It can be seen, that the hysteresis based MPC is advantageous compared to the finite control set MPC. For the same switching frequency, both MPC algorithms are providing better current distortion compared to the PI Control, or, for the same THDi, the switching frequency can be reduced. Especially for the region of $\frac{f_{S}}{f_{e l}}<10$, where high-speed and high power machines are often operated, the improvement increases significantly. For higher switching frequencies, the THDi of the MPC algorithms is limited by the control frequency, defining the minimum turn-on time of the semiconductors.

TABLE I

MACHINE SETUP DATA

\begin{tabular}{cc}
\hline$P_{\text {PMSM,rated }}$ & $22 \mathrm{~kW}$ \\
$n_{\text {rated }}$ & $2000 \mathrm{rpm}$ \\
$f_{\text {el }}$ & $100 \mathrm{~Hz}$ \\
pole pairs & 3 \\
$L_{\mathrm{s}, \mathrm{dq}}$ & $2.2 \mu \mathrm{H}$ \\
$R_{\mathrm{s}}$ & $0.1 \Omega$ \\
\hline
\end{tabular}

TABLE II

CONVERTER SETUP DATA

\begin{tabular}{cc}
\hline$V_{\mathrm{DC}}$ & $560 \mathrm{~V}$ \\
$f_{\text {Control }}$ & $20 \mathrm{kHz}$ \\
$T_{\text {deadtime }}$ & $2 \mu \mathrm{s}$ \\
\hline
\end{tabular}

Another important aspect for MPC is the choice of the sampling frequency. In Figure 4 the THDi of the motor current over the effective switching frequency at nominal speed is shown for different sampling frequencies $f_{S}$. It can be seen, that for low carrier ratios, the outcome is very similar. This changes, when a ratio of sampling to effective switching frequency of approximately $\frac{f_{s w, e f f}}{f_{S}}=15$ is reached. The sampling time limits the minimum pulse width. Thus, smaller and more effective switching instances reducing the THDi are not possible. Secondly, a small improvement at higher pulse ratios can be seen for a higher switching frequency. In addition, the smaller possible pulse widths are having an positive effect, as well as the fact, that due to the higher sampling frequency, the probability of finding effective trajectories is increased. 


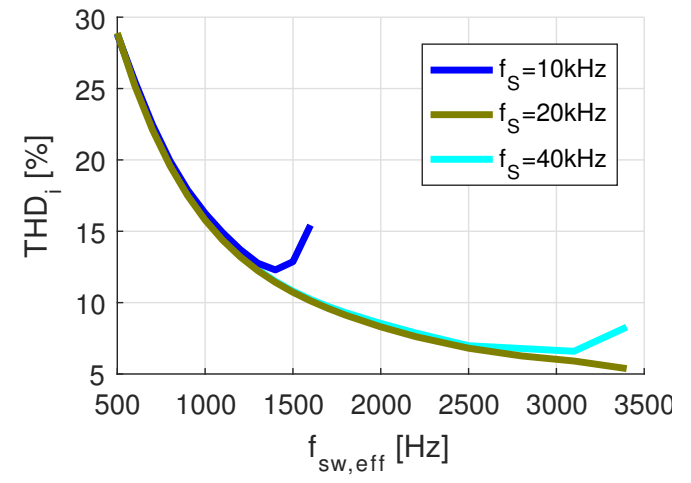

Fig. 4. Comparison of total harmonic motor current distortion $T H D_{i}$ over (effective) switching frequency $f_{s w(, e f f)}$.

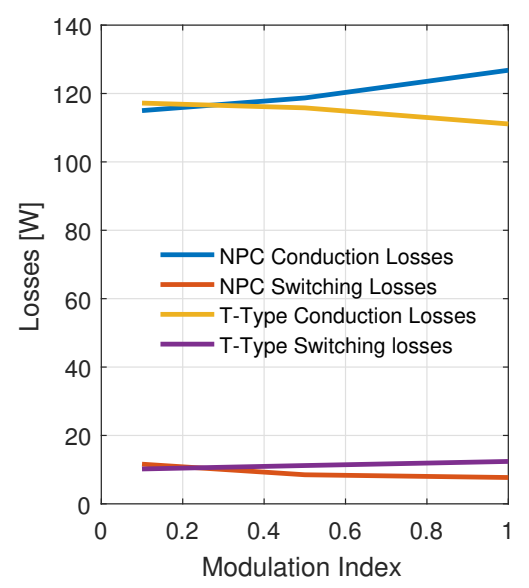

Fig. 5. Comparison of switching and conduction losses for NPC and T-Type Converter.

\section{A. Power semiconductor rating}

To compare the cost of different inverter topologies, the power semiconductor design rating is chosen as criteria. Discrete Infineon IGBTs are used. The evaluation of the semiconductor rating and losses are based on data sheet parameters. The comparison of the power semiconductor rating of the NPC and T-Type is shown in III. The procedures are shown for example in [9] or [10]. It can be seen, that for the Converter and PMSM shown in I and II, the NPC has a lower rating, $0.438 \mathrm{MVA}$ compared to $0.468 \mathrm{MVA}$ for the T-Type.

\section{B. Losses}

In Fig. 5 the conduction and switching losses for NPC and T-Type are compared. As the switching frequency is very small, the conduction losses are mainly defining the overall losses. At an modulation index of 0.25 , a break even point can be found. At higher modulation factors, the T-Type is having lower losses, while at small modulation factors or higher switching frequencies, the NPC is providing better efficiency. For a modulation factor of $M=1$ and a pulse ratio of $\frac{f_{s w, e f f}}{f_{e} l}=8$, the loss distribution of NPC and T-Type is shown in Fig. 6 and Fig. 7.

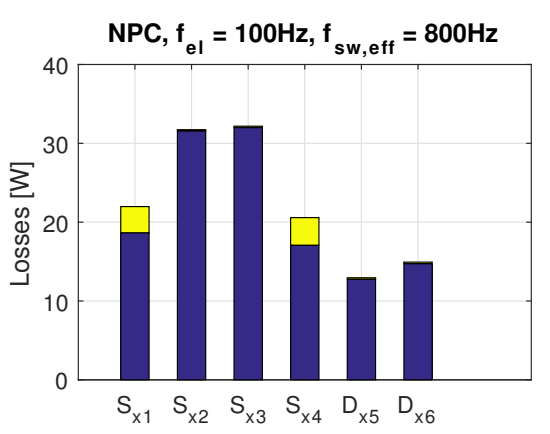

Fig. 6. Losses for NPC, M=1: Conduction losses (blue), switching losses (yellow).

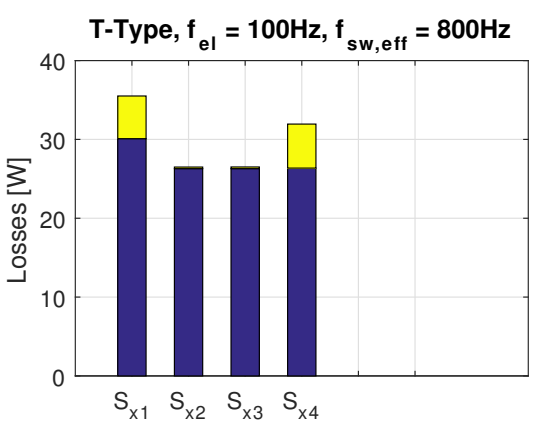

Fig. 7. Losses for T-Type, $\mathrm{M}=1$ : Conduction losses (blue), switching losses (yellow).

\section{EXPERIMENTAL RESULTS}

The simulation results of the current controllers are validated by experiments with a $22 \mathrm{~kW}$ Siemens PMSM, connected to a DC load machine. The DC link of the converter is connected to a $10 \mathrm{~kW}$ DC voltage source. The waveform of the output current is measured and recorded by a Tektronix DPO3014 Oscilloscope with a Tektronix TCP0030 Current Probe. The inductance and resistance of the machine were measured with a Sourcetronic ST2826A LCR meter and are given in I. A DSpace MicroLabBox is used to control the system. The laboratory setup is shown Fig.8.

In Figure 9 the simulated and measured results are compared. All three control algorithms show good correlation of simulation and experimental results. For the MPC algorithms,

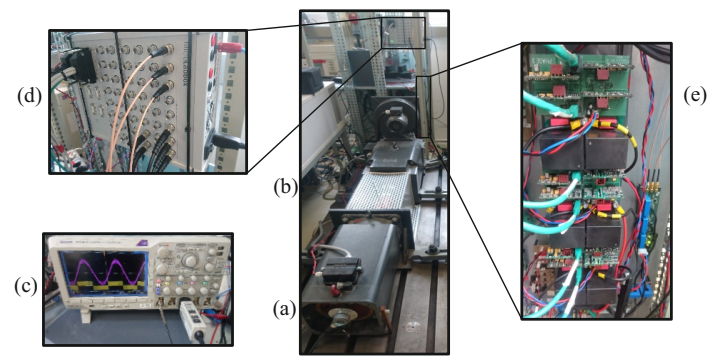

Fig. 8. Experimental setup: (a) Siemens PMSM, (b) DC Load machine, (c) Oscilloscope, (d) DSpace MicroLabBox, (e) Converter. 
TABLE III

COMPARISON OF POWER SEMICONDUCTOR RATING FOR DIFFERENT CONVERTER TOPOLOGIES

\begin{tabular}{lccccc}
\hline & Semiconductor & $V_{C E}[\mathrm{~V}]$ & $I_{\text {rated }}[\mathrm{A}]$ & Number of IGBTs / Diodes & Rating [MVA] \\
\hline 3-Level NPC & Infineon IKW50N60T / Infineon IDW40G65C5 & 600 & $50 / 40$ & $12+6$ & 0.438 \\
\hline 3-Level T-Type & Infineon IKW40T120 / Infineon IKW50N60T & $1200 / 600$ & $40 / 50$ & $6+6$ & 0.468 \\
\hline
\end{tabular}

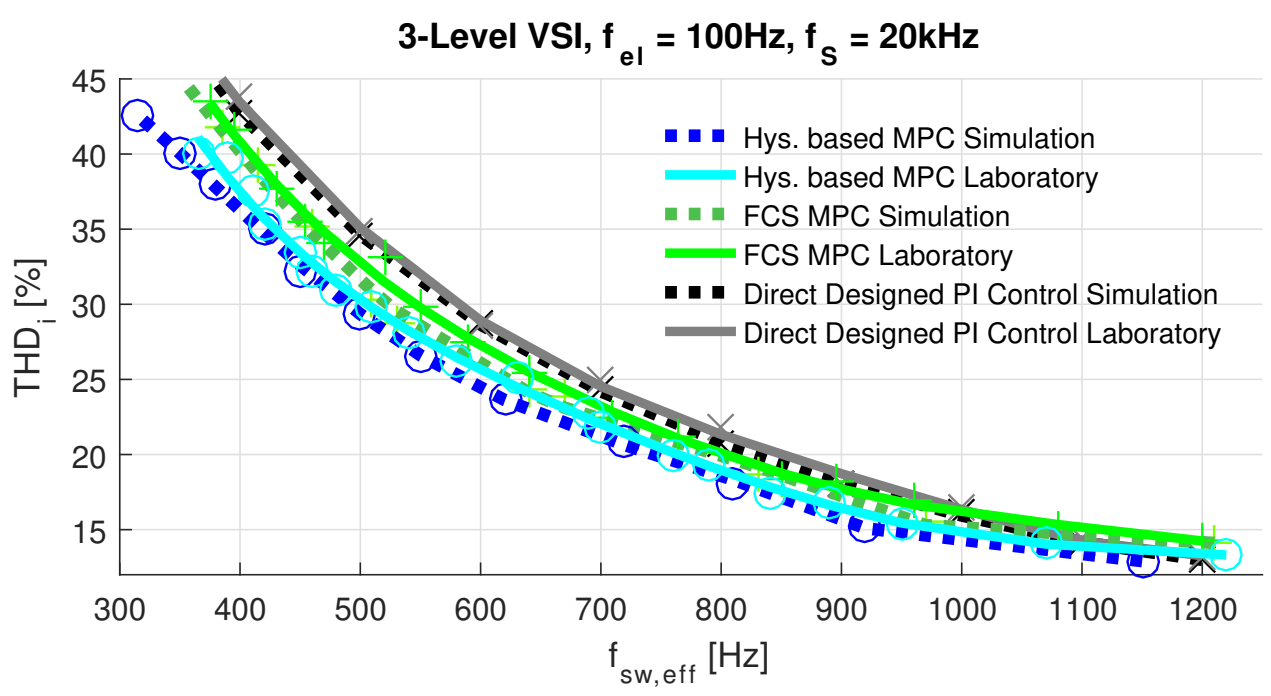

Fig. 9. Comparison of (effective) switching frequency over THDi for simulation (dashed lines) and experimental results (solid lines) of hys. based MPC (blue), FCS MPC (green), and PI Control (black).

small deviations can occur due to saturation of the magnets, saliency of the machine, or other parameter uncertainties. It can be proven, that the hysteresis based MPC is providing the best results.

FCS (green) and hys. based MPC (blue) are favorable compared to PWM based PI Control (black). Only at very high switching frequencies, where the THDi of the MPC algorithms is limited by the control frequency, the PI Control is providing better results.

\section{CONCLUSION}

In this paper finite control set and hysteresis based model predictive control for NPC and T-Type are presented and compared for a PMSM in case of low carrier ratio. While the T-Type is preferable for high modulation indexes, the NPC gets more advantageous for lower modulation indexes, or if the switching frequency is increased. The NPC is having a smaller power semiconductor rating. The hys. based MPC is providing a better THDi or lower switching frequency, compared to FCS MPC. Both MPC algorithms are favorable compared the PWM based PI Control.

\section{ACKNOWLEDGMENT}

The research leading to these results has received fundings from the European Union/Interreg V-A - Germany-Denmark, under the PE:Region Project.

\section{REFERENCES}

[1] A. Borisavljevic, H. Polinder, and J. Ferreira, "On the speed limits of permanent-magnet machines," IEEE Transactions on Industrial Electronics, vol. 57, no. 1, pp. 220-227, jan 2010.

[2] J. C. R. Martinez, R. M. Kennel, and T. Geyer, "Model predictive direct current control," in 2010 IEEE International Conference on Industrial Technology. IEEE, 2010.

[3] W. Xie, X. Wang, F. Wang, W. Xu, R. M. Kennel, D. Gerling, and R. D. Lorenz, "Finite-control-set model predictive torque control with a deadbeat solution for PMSM drives," IEEE Transactions on Industrial Electronics, vol. 62, no. 9, pp. 5402-5410, sep 2015.

[4] J. Holtz, "Advanced PWM and predictive control—an overview," IEEE Transactions on Industrial Electronics, vol. 63, no. 6, pp. 3837-3844, jun 2016.

[5] J. Scoltock, T. Geyer, and U. K. Madawala, "A comparison of model predictive control schemes for MV induction motor drives," IEEE Transactions on Industrial Informatics, vol. 9, no. 2, pp. 909-919, may 2013.

[6] J. D. Barros, J. F. A. Silva, and E. G. A. Jesus, "Fast-predictive optimal control of npc multilevel converters," IEEE Transactions on Industrial Electronics, vol. 60, no. 2, pp. 619-627, feb 2013.

[7] H. Kim, M. W. Degner, J. M. Guerrero, F. Briz, and R. D. Lorenz, "Discrete-time current regulator design for AC machine drives," IEEE Transactions on Industry Applications, vol. 46, no. 4, pp. 1425-1435, jul 2010.

[8] S. Bolognani, S. Bolognani, L. Peretti, and M. Zigliotto, "Design and implementation of model predictive control for electrical motor drives," IEEE Transactions on Industrial Electronics, vol. 56, no. 6, pp. 19251936, jun 2009.

[9] S. Brueske, B. Benkendorff, R. Kulpe, and F. W. Fuchs, "Comparison of the power semiconductor design rating of different inverter topologies for the drive inverter of electric vehicles," in 2015 IEEE Energy Conversion Congress and Exposition (ECCE). IEEE, sep 2015.

[10] M. Schweizer, T. Friedli, and J. W. Kolar, "Comparative evaluation of advanced three-phase three-level inverter/converter topologies against two-level systems," IEEE Transactions on Industrial Electronics, vol. 60, no. 12, pp. 5515-5527, dec 2013. 